\title{
O Condrito Rio do Pires: aspectos petrográficos e mineraloquímicos
}

\author{
Wilton Pinto de CARVALHO ${ }^{1,2}$, Débora Correia RIOS ${ }^{1,2}$, Maria Elizabeth ZUCOLOTTO ${ }^{3}$, Herbet \\ CONCEIÇÃO ${ }^{1,2,4}$, Amanda Araújo TOSI ${ }^{5}$ \& Murilo Magno GOMES ${ }^{2}$
}

Programa de Pós-graduação em Geologia, Universidade Federal da Bahia. Rua Barão de Jeremoabo, 147, CEP 40.170-115, Salvador, BA, Brasil (doutor.wilton@gmail.com.br).

2 Grupo de Pesquisa Laboratório de Petrologia Aplicada à Pesquisa Mineral. Rua Barão de Jeremoabo, 147, CEP 40.170-115, Salvador, BA, Brasil (dcrios@ufba.br), (murvacio@hotmail.com).

Museu Nacional, Universidade Federal do Rio de Janeiro. Quinta da Boa Vista. São Cristóvão, CEP 20940-040, Rio de Janeiro, RJ, Brasil (mezucolotto@globo.com).

4 Programa de Pós-Graduação em Geociências e Análise de Bacias, Universidade Federal de Sergipe. Av. Marechal Rondon, Jardim Rosa Elze, CEP 49.100-000. São Cristóvão, SE, Brasil (herbet@ufs.br).

Labsonda, Instituto de Geociências, Universidade Federal do Rio de Janeiro. Av. Athos da Silveira Ramos, 274, Cidade Universitária, Ilha do Fundão, CEP 21044-020, Rio de Janeiro, RJ, Brasil (amandatosi@hotmail.com).

Carvalho, W.P. de, Rios, D.C., Zucolotto, M.E., Conceição, H., Tosi, A.A. \& Gomes, M.M. 2018. O Condrito Rio do Pires: aspectos petrográficos e mineraloquímicos. Pesquisas em Geociências, 45: e0666.

DOI: https://doi.org/10.22456/1807-9806.88647

Resumo. 0 O meteorito Rio do Pires é um condrito tipo L6 achado antes de 1992 na Bahia, Brasil, em data desconhecida, tendo seu registro publicado no Meteoritical Bulletin em 1994, através de análise simplificada requerida para esse procedimento, apresentada por Adrian Brearley da Universidade do Novo México, E.U.A. Esse estudo objetiva ampliar os dados existentes sobre esse meteorito, através do detalhamento de suas características petrográficas, químicas e mineralógicas. Foram realizadas análises em três lâminas polido-delgadas e em uma amostra de mão, utilizando microscópio petrográfico e lupa petrográfica estereomicroscópica, microssonda eletrônica (EPMA) e microscopia eletrônica de varredura (MEV). A análise petrográfica permitiu constatar a existência de veios de choque resultantes de evento colisional do corpo parental que originou esse meteorito. Aproximadamente $93 \%$ dos minerais que compõem essa rocha são transparentes, predominando cristais de olivina, piroxênio e plagioclásio, nesta ordem. Os minerais opacos são representados por grãos de Fe-Ni metálicos, troilita, cromita e whitlockita (merrilita). A olivina é predominantemente magnesiana $\left(\mathrm{Fa}_{25}\right)$. 0 piroxênio é a enstatita e o plagioclásio oligoclásio. A mineraloquímica observada é similar a do bem estudado meteorito Suizhou, um condrito do tipo L6. A matriz demonstra sinais de alta recristalização e presença de maskelinita, um importante indicador de choque, sendo significativa para o entendimento da história evolucional do Rio do Pires. Os novos dados indicam um grau de choque entre S4 e S5 para este meteorito, em vez do grau S6 proposto quando de seu registro no Meteoritical Bulletin.

Palavras-chave. Condrito, meteorito, L6, Rio do Pires.

Abstract. The Rio do Pires Chondrite: Petrographic and Mineral Chemistry Features. The Rio do Pires meteorite is a L6 chondrite found in Bahia, Brazil, at an unknown date. It was registered at the Meteoritical Bulletin in 1994, through a simplified analysis required for this procedure, presented by Adrian Brearley, University of New Mexico, USA. This paper aims to broaden the existing data on this meteorite through detailed petrographic, chemical and mineralogical analysis. Such analyses were performed on three polished thin sections and a hand sample, using a petrographic microscope and stereomicroscopic petrographic magnifying glass, electron microprobe (EPMA) and scanning electron microscope (MEV). The petrographic analysis shows the existence of shock veins caused by an impact event of the parent body that originated this meteorite. Approximately $93 \%$ of the minerals that compose this rock are transparent, predominating crystals of olivine, pyroxene and plagioclase, in this order. Opaque minerals are represented by Fe-Ni metal grains, troilite, chromite, and whitlockite (merrilite). Olivine is predominantly magnesian ( $\mathrm{Fa} \sim 25 \%)$. The pyroxene is the enstatite and the plagioclase is oligoclase. The observed mineral chemistry is similar to that of the well-studied Suizhou meteorite, a chondrite type L6. The matrix shows signs of high re-crystallization and presence of maskelynite, an important indicator of shock, being significant for understanding the evolutionary history of Rio do Pires. The new data indicate a S4 to S5 shock grade for this meteorite, instead of the S6 grade proposed when it was submitted to the Meteoritical Bulletin. Keywords. Chondrite, meteorite, L6, Rio do Pires. 


\section{Introdução}

Meteoritos chocam-se com a Terra desde os primórdios do Sistema Solar e são definidos como rochas e ligas metálicas de Fe-Ni de origem espacial que caíram na superfície terrestre e foram recuperados. São amostras extraterrestres passíveis de estudos petrográficos, químicos e isotópicos, os quais permitem determinar suas texturas e composições, assim como datar eventos relacionados à formação e evolução de astros que constituem o Sistema Solar. 0 banco de dados mantido pela Meteoritical Society, entidade responsável pela nomenclatura de meteoritos, tem registrado mais de 50 mil meteoritos, inclusive os espécimes coletados na Antártida e desertos orientais, demonstrando que o número de achados e quedas dessas rochas espaciais é significativo (Grossman, 2017).

No Brasil, o Museu Nacional mantém registros da coleção de meteoritos brasileiros, cujo número ainda é pequeno (71 exemplares), comparativamente às coleções de outros países, como os Estados Unidos que tem 1.831 meteoritos registrados. A coleção brasileira é constituída por 35 exemplares $(49,29 \%)$ de meteoritos rochosos, 35 de ferro $(49,29 \%)$ e um único misto, um palasito composto de ferro e olivina $(1,42 \%)$. Essa proporção é discordante em relação à frequência mundial de quedas e achados, onde os meteoritos rochosos (condritos e acondritos) correspondem a $97 \%$ e os metálicos (férreos e palasitos) a $3 \%$. Explica-se essa discordância, também encontrada em coleções de outros países, pela alta densidade e tamanho dos meteoritos metálicos, o que facilita seu reconhecimento, e pela grande resistência ao intemperismo, que os fazem permanecer longo tempo sem se decompor até serem achados.

A distribuição geográfica destas quedas e achados pelos estados federativos também é irregular, cabendo a Minas Gerais a primeira posição com 20 espécimes, seguida pelo Rio Grande do Sul com oito, Goiás com sete, São Paulo e Bahia com seis, cada um. Dos seis meteoritos baianos, dois são do tipo condritíco, denominados Rio do Pires e Três Irmãos, sendo o primeiro objeto deste artigo. Não há explicação científica para Minas Gerais abrigar $29 \%$ do total de meteoritos do Brasil, uma vez que esses corpos caem aleatoriamente na superfície terrestre, podendo-se aventar a possibilidade de uma maior presença de geólogos e mineradores naquele estado favorecer o reconhecimento dos achados e quedas.

O histórico do meteorito Rio do Pires é bastante vago. A amostra foi doada ao primeiro autor deste artigo em 1992 pelo Prof. Shiguemi Fujimori, catedrático em petrologia do Instituto de Geociências da Universidade Federal da Bahia, que a obteve de um ex-aluno, o geólogo Ismael Medeiros, que informou tê-la recebido do garimpeiro Luís Dias enquanto trabalhava na região de Rio do Pires, mais especificamente no povoado de Ibiajara. A data do achado é desconhecida, estimando-se ter acontecido em 1981.

O município de Rio do Pires localiza-se na região Sudoeste da Bahia, distando cerca de 596 $\mathrm{km}$ da capital do estado (Fig. 1). 0 acesso por via rodoviária, a partir de Salvador, ocorre através da BR 324, BR 242 e BA 152. A sede do município tem como coordenadas geográficas Latitude $13^{\circ} \mathrm{e}$ Longitude $42^{\circ}$. A altitude é de $551 \mathrm{~m}$, com área de $892,8 \mathrm{~km}^{2}$.

Devido à ausência de informações seguras quanto ao achado, em 1994 o meteorito foi denominado Rio do Pires e as coordenadas da sede desse município foram utilizadas para fins de registro do espécime junto ao Meteoritical Bulletin, conforme notificação feita pelo Dr. Adrian Brearley, do Instituto de Meteorítica da Universidade do Novo México, Estados Unidos que o classificou como um condrito ordinário, tipo L6, publicando análise resumida no Meteoritical Bulletin no 77 (Wlotzka, 1994).

Desde então, publicou-se apenas um resumo (Antonello \& Zucolotto, 2001) sobre as características petrográficas desse meteorito, existindo assim uma carência marcante de trabalhos acadêmicos sobre esse importante material extraterrestre. 0 presente trabalho tem por objetivo descrever e caracterizar a mineralogia e petrologia desta rocha em seus aspectos petrográficos e mineraloquímicos, contribuindo assim para a ampliação dos estudos sobre os meteoritos brasileiros. 


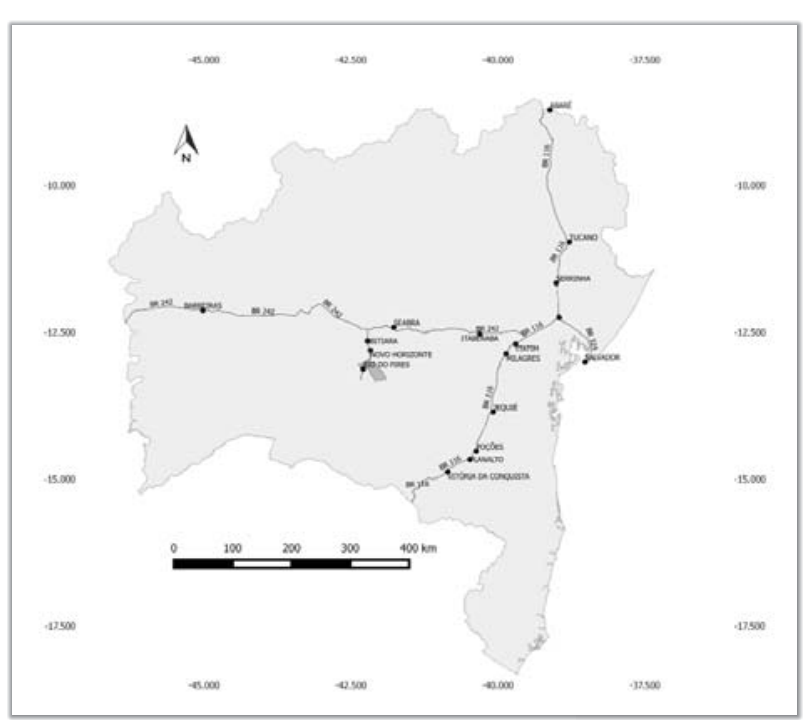

Figura 1. Mapa do Estado da Bahia com a localização e acesso rodoviário para o município de Rio do Pires, onde provavelmente o meteorito foi recuperado.

Figure 1. Map of Bahia State with road access to Rio do Pires town, where the meteorite was probably found.

\section{Aspectos e relevância do estudo de condritos}

São reconhecidos três grandes grupos de meteoritos: pétreos ou rochosos, férreos ou metálicos e mistos. 0 grupo mais numeroso é formado pelos rochosos que respondem por $97 \%$ de todas as quedas e achados de meteoritos na Terra. Por sua vez, esse grupo subdivide-se em condritos e acondritos, palavras derivadas do grego que significam respectivamente com côndrulos e sem côndrulos. Os condritos não sofreram processos de diferenciação, sendo compostos, portanto, por material primitivo, formado nos primórdios do Sistema Solar, antes do surgimento dos asteroides e planetas.

\subsection{Condritos}

Condritos são um tipo de meteorito rochoso caracterizado pela presença de partículas esféricas, geralmente submilimétricas, compostas principalmente de silicatos (olivina, piroxênio e plagioclásio), troilita ( $\mathrm{FeS}$ ), liga metálica $\mathrm{Fe}-\mathrm{Ni}$, cromita, minerais fosfatados e vidro. Krot et al. (2005) propuseram a mais recente classificação dos meteoritos condritos, baseada na mineralogia e petrologia, origem similar e histórico de formação parecido. De acordo com estes autores, os meteoritos condritos subdividem-se em seis classes:(i) Carbonáceos: Inclui oito grupos denominados CI, CM, CO,
$\mathrm{CR}, \mathrm{CB}, \mathrm{CH}, \mathrm{CV}$ e CK onde a primeira letra (C) significa carbonáceo, e a segunda representa o nome do meteorito tipo de cada série: (I) Ivuna, (M) Mighei, (O) Ornans, (R) Renazzo, (B) Bencubbin, (H) ALHA85005, (V) Vigarano, e (K) Karoonda; (ii) Ordinários. Essa classe é a mais abundante, daí o nome ordinário no sentido de comum, respondendo por aproximadamente $85 \%$ de todos os meteoritos rochosos registrados pelo Meteoritical Bulletin Database. 0 conteúdo total de Fe nos meteoritos condritos ordinários é utilizado para subclassificar essas rochas em três tipos e cinco níveis representados por letras: $\mathrm{H}$ (High/Alto: 25 a 30\% Fe total), L (Low/Baixo: 22 a 25\% Fe total), e LL (Low-Low/Muito Baixo: 19 a 22\% Fe total); (iii) Enstatitos: A exemplo da classe dos ordinários, os enstatitos (E) também sub-classificam-se em EH e EL (High/Alto, $>25 \%$ e Low/Baixo, $\leq 25 \%$ ) conforme a concentração do elemento Fe e outros metais em suas massas. As três demais classes são mais raras e definidas de acordo com o nome do meteorito de referência - (iv) semelhantes ao Rumuruti e (v) semelhantes ao Kakangari - enquanto os restantes são coletivamente denominados de (vi) Anômalos.

\subsection{Tipos petrológicos}

Os meteoritos condritos também são classificados em tipos petrológicos, cujas características diferem em razão de alterações provocadas pela hidratação, intemperismo e/ou metamorfismo. Essa classificação tem 7 níveis (Van Schmus \& Wood, 1967), sendo o nível 3 - o mais primitivo - atribuído a rochas que preservam quase que integralmente suas características ígneas, ricas em côndrulos bem definidos. Os tipos 4, 5, 6 e 7 apresentam efeitos de metamorfismo térmico, tendo sido submetidos a temperaturas que variaram de 400 a mais de $950^{\circ} \mathrm{C}$, exibindo côndrulos menos definidos a partir do tipo 5, ou ausência dos mesmos no tipo 7. Os tipos 1 e 2 sofreram alterações por hidratação, tendo um conteúdo de $\mathrm{H}_{2} \mathrm{O}$ entre 2 e $20 \%$. Assim, a nomenclatura de um meteorito condrito expressa sua classe (composição química), conteúdo de ferro total (H, L, LL), e tipo petrológico (1 a 7). 


\subsection{Côndrulos}

Estudos em côndrulos têm atraído muita atenção nos últimos anos pelas importantes informações que trazem sobre os primórdios da formação dos astros do Sistema Solar, incluindo a Terra. Acredita-se que os côndrulos foram formados a partir de minerais condensados da nuvem de gás e poeira cósmica que originou o Sistema Solar e que posteriormente sofreram fusão em diferentes regiões da nebulosa (Hutchison, 2004). Uma vez formados e reunidos em massas maiores, os côndrulos originaram corpos não diferenciados (planetesimais condríticos) que mantiveram suas estruturas físicas e composições químicas inalteradas (meteoritos condritos primitivos). Processos de diferenciação e/ou alterações metamórficas resultaram no desaparecimento dos côndrulos devido à fusão parcial ou total, originando meteoritos diferenciados, que incluem os meteoritos acondriticos e metálicos, em procedimentos evolutivos similares aos que resultaram nas estruturas acamadadas dos planetas rochosos (Messenger et al., 2006, McSween Jr. et al., 2006). Os meteoritos condritos são, portanto, rochas não diferenciadas que preservaram suas estruturas internas resultantes da acresção de grãos que se aglutinaram formandos esferas geralmente poliminerálicas que podem se apresentar íntegras ou metamorfizadas.

\subsection{Inclusões ricas em cálcio}

Em um mesmo condrito, os côndrulos podem possuir distintas composições mineralógicas e texturas. Experimentos realizados em laboratório por Hewins \& Connolly Jr. (1996) determinaram que os côndrulos fundem-se entre 1.500 e 1.850 ${ }^{\circ} \mathrm{C}$, conforme o maior ou menor conteúdo de minerais refratários.

Outra característica importante dos meteoritos condritos é a presença de inclusões ricas em cálcio e alumínio, denominadas CAIs, que são formadas por minerais de alta temperatura tais como olivina, coríndon, hibonita, perovskita, anortita, melilita e espinélio. Essas inclusões em meteoritos condritos são anteriores aos próprios côndrulos e representam o material mais antigo já datado no Sistema Solar, atingindo 4.567,2 \pm 0,6 Ma (Amelin et al., 2002).

\section{Materiais e métodos}

\subsection{Materiais}

0 espécime que se encontrava no Instituto de Geociências da UFBA pesava 118 gramas, com sua aresta maior medindo $4 \mathrm{~cm}$ (Fig. 2A). Uma das faces estava serrada (Fig. 2B) sugerindo retirada de fatia para análise da textura interior e confecção de lâmina petrográfica, entretanto não foram localizados resultados de quaisquer exames realizados na UFBA ou em outra instituição de pesquisa, tampouco foram localizados outros fragmentos da amostra.

A Universidade do Novo México e o Museu Nacional são as instituições depositárias de amostras desse meteorito. Foi utilizada neste trabalho a massa remanescente ( $35 \mathrm{~g}$ ) do fragmento original - a qual integra a coleção de meteoritos do primeiro autor desse trabalho - uma fatia metalizada para análise através de Microscopia Eletrônica de Varredura (MEV) e três lâminas polido-delgadas.

\subsection{Métodos}

A amostra de mão (35 g) e uma pequena fatia polida do meteorito foram analisadas a olho nu e com lupa estereoscópica binocular. Três lâminas polido-delgadas foram preparadas pelo método convencional e na espessura padrão $(0,3$ $\mathrm{mm}$ ), sendo analisadas com microscópio petrográfico Zeiss Axioskop 40 equipado com Axiocam de alta resolução e aplicativo Axiovision versão 4.7, nos laboratórios do Museu Nacional, UFRJ, sob luz transmitida, polarizada e refletida.

As análises mineraloquímicas das fases essenciais e algumas acessórias utilizaram a microssonda eletrônica JXA-JEOL 8230, com cinco espectrômetros, equipada com WDS/EDS, e utilizando uma câmera AxionCam HRC-AX10 e o software Zen2 Core, localizados no Labsonda do Instituto de Geociências da UFRJ. As condições analíticas foram de aceleração potencial $15 \mathrm{kV}$ e um feixe de 20 nA. Padrões de referência de composições bem conhecidas foram utilizados para as análises quan- 


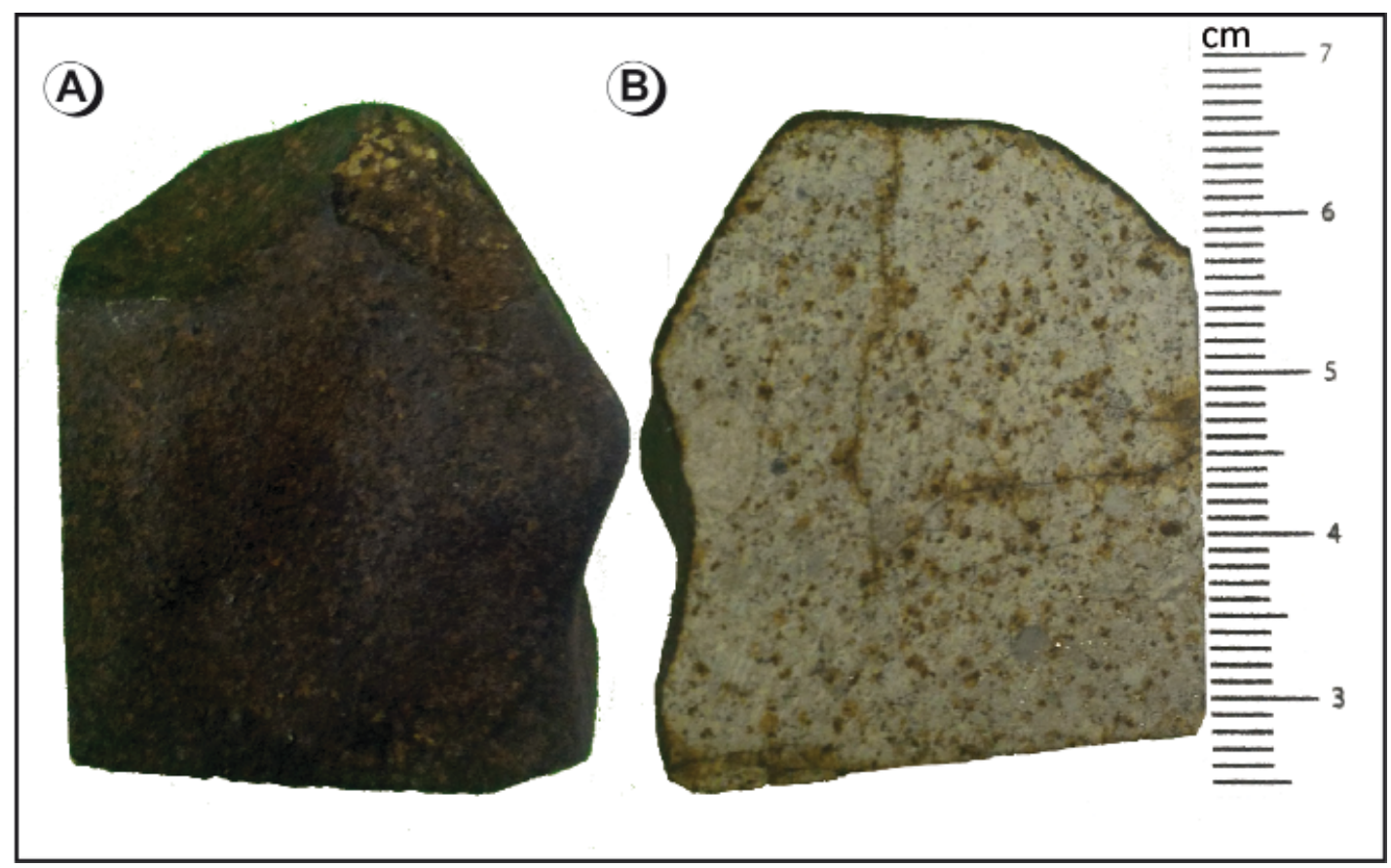

Figura 2. Amostra do meteorito Rio do Pires. A) Fragmento com crosta; B) Face de corte da massa remanescente, exibindo diversos veios finos e retilíneos.

Figure 2. Sample from Rio do Pires meteorite. A) Fragment with crust. B) Cut face of remnant mass, exhibiting various fine and straight veins.

titativas dos minerais de interesse.

Uma fatia do meteorito foi polida e metalizada com ouro, sendo analisada por Microscopia Eletrônica de Varredura (MEV) no laboratório multiusuário da Universidade Federal de Sergipe. $O$ equipamento utilizado é da marca TESCAN modelo VEJA 3-LMU com detectores acoplados de elétrons secundários, elétrons retroespalhados e de cátodo luminescência. 0 espectrômetro de energia dispersiva (EDS) acoplado ao MEV é da Oxford Instruments, modelo X-Act, e tem resolução de 125 $\mathrm{eV}$. As condições analíticas utilizadas durante as análises foram uma aceleração potencial de $20 \mathrm{kV}$ e corrente de $15 \mathrm{nA}$ e $17 \mathrm{nA}$, gerando um feixe de elétrons com diâmetros de 0,3 $\mu \mathrm{m}$ e $0,4 \mu \mathrm{m}$, respectivamente.

\section{Resultados}

\subsection{Análises petrográficas}

Na avaliação de meteoritos, em especial de condritos, os estudos petrográficos permitem avaliar o caráter primitivo dessas rochas que não passaram por processos de diferenciação e apresentam textura única - a presença de côndrulos - sem similar na Terra.
Os estudos petrográficos das seções polidas do meteorito Rio do Pires tiveram como objetivos principais: (i) investigar suas assembléias minerais e relacionamentos texturais e estruturais, (ii) inferir as paragêneses minerais, (iii) selecionar aspectos importantes para detalhamento com o microscópio eletrônico de varredura e microssonda eletrônica. Adicionalmente buscou-se avaliar as estruturas internas e feições de deformação resultantes de possíveis impactos que o corpo parental sofreu no espaço. Esses efeitos causam alterações nos minerais que compõem o meteorito, permitindo inferir o grau do choque sofrido (Stöffler et al., 1991).

No meteorito Rio do Pires a matriz e a parte condrítica representam $92,7 \%$ da amostra em volume, os minerais opacos totalizam 5,3\% e a crosta $2,0 \%$. Veios de choque formados durante evento colisional no espaço são facilmente visíveis a olho nu e através de lupa. A amostra original era totalmente revestida por uma crosta de fusão preta fina $(0,3$ a $0,5 \mathrm{~mm})$, preservada nas fatias analisadas e amostra de mão. Essa crosta vitrificada foi formada durante a passagem do meteorito pela atmosfera terrestre (Fig. 2).

0 fragmento analisado ( $35 \mathrm{~g}$ ) apresenta exteriormente numerosos regmalitos (mossas), crosta 
de fusão primária e secundária, esta última indicadora de fragmentação do meteorito durante o vôo através da atmosfera terrestre. A parte interna é de cor cinza claro, apresentando textura tipicamente condrítica, com muitos côndrulos fragmentados, alongados ou circulares, cujos limites são mal definidos e difíceis de ser observados. Inclusões metálicas de Fe-Ni e minerais opacos destacam-se em uma matriz de fina granulação com veios de choque bem delineados (Fig. 2B).

De acordo com Xie \& Chen (2015), a mineralogia destas rochas é geralmente muito simples, consistindo de olivina, piroxênio pobre em $\mathrm{Ca}$, e ligas de Fe-Ni (kamacita e taenita). Minerais varietais comuns incluem plagioclásio, diopsídio, e troilita, enquanto a mineralogia acessória é constituída por cromita, whitlockita (merrilita), e cloro-apatita. Podem ainda ocorrer cobre nativo, pigeonita, pentlandita, ilmenita, mackinawita, bravoita e calcopirita.

De acordo com medidas estatísticas feitas a partir de um fotomosaico da lâmina delgada utilizando o programa ImageJ (National Institutes of Health, 2013), o condrito Rio do Pires contém $94,72 \%$ de minerais transparentes (Fig. 3A e B) e $5,28 \%$ de minerais opacos, em volume (Fig. 3C). 0 meteorito apresenta textura cristalina granular, com vários côndrulos que ainda preservam limites discerníveis em relação à matriz, enquanto muitos outros possuem limites indistintos, indicando que a rocha foi submetida a um evento metamórfico de elevado grau térmico (Fig. 3A e B).

A matriz mostra sinais de alta recristalização com cristais uniformes de olivina, piroxênio, plagioclásio, minerais opacos e, adicionalmente, hematita e goethita ou lepidocrosita, as quais formam as fases secundárias identificadas, resultantes de intemperismo.

A maskelinita - um vidro denso resultante da fusão do plagioclásio - também foi identificada, sendo sua presença significativa para o entendimento da história colisional da rocha, pois é uma importante evidência de choque (Chen \& El Goresy, 2000).

A textura condrítica do meteorito Rio do Pires está preservada e pode ainda ser reconhecida tanto no espécime de mão quanto em lâmina polidodelgada (Fig. 2 e 3). Os côndrulos têm composição ferro-magnesiana e apresentam-se sob formatos arredondados (Fig. 3B) ou alongados, a maioria fragmentada e alguns com estrutura radiante fibrosa difusa (Fig. 3B). Eles medem em média 1,64 mm, variando de 0,3 a $5 \mathrm{~mm}$ em diâmetro.

Foram identificados côndrulos porfiríticos compostos de olivina, de piroxênio e de olivinapiroxênio (Fig. 4). Entretanto, em sua maioria,
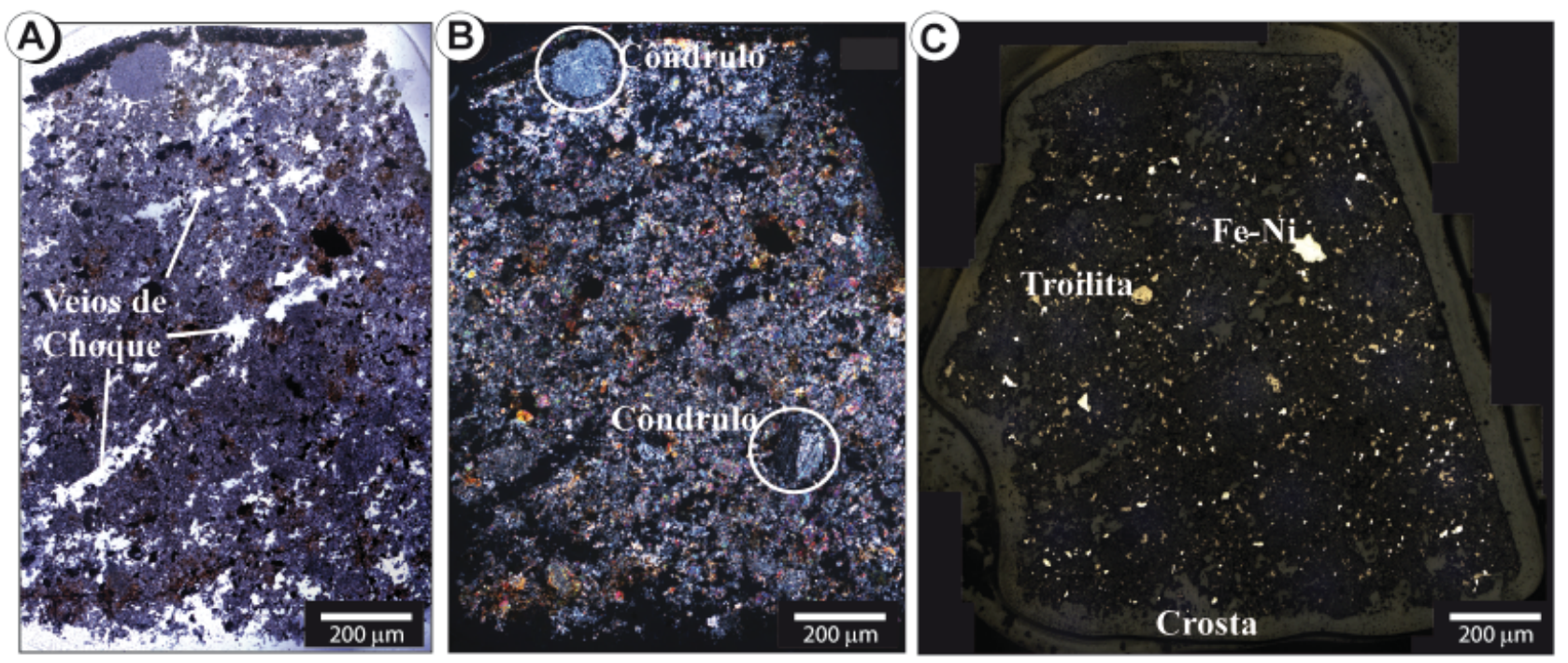

Figura 3. Fotomosaicos de uma lâmina polida do meteorito Rio do Pires. Minerais transparentes e côndrulos observáveis em (A) Luz Transmitida; e (B) Luz Polarizada. Mineralogia opaca evidenciada na imagem de luz refletida após tratamento com nital (C). As fases de cor branca correspondem à liga Fe-Ni e os cristais amarelo-dourado são troilitas.

Figure 3. Photo assemblage from a thin section of meteorite Rio do Pires. Transparent minerals and condrules observed at (A) Transmitted light and (B) Polarized light. Opaque minerals highlighted by the image under reflected light after etching with nital (C). White phases are Fe-Ni alloy and golden-yellow crystals are troilites. 
os côndrulos são granulares, compostos também desses dois minerais, isoladamente ou combinados. Outro tipo de côndrulo encontrado nesse meteorito é composto por olivina barrada. As fases metálicas predominantes são a kamacita e a taenita, além de existir quantidades acessórias de troilita, cromita e fosfatos.

\subsection{Análises mineraloquímicas}

\subsubsection{Minerais formadores de rochas}

As análises mineraloquímicas do meteorito Rio do Pires foram subdivididas em minerais formadores de rochas (olivina, piroxênio e plagioclásio), minerais opacos (liga de $\mathrm{Fe}-\mathrm{Ni}$, troilita, cromita), e fosfatos (merrilita, cloroapatita). Análises de dez pontos investigados por microssonda eletrônica (EPMA) e sete áreas observadas através de microscopia eletrônica de varredura (MEV) confirmam os achados petrográficos e permitiram quantificar as composições das fases minerais observadas (Fig. 5). Além disso, o estudo por MEV revelou a existência e composição do mineral fosfatado whitlockita (merrilita).

\section{Olivina}

Olivina é o principal constituinte do meteorito Rio do Pires. Os cristais de olivina apresentam alta birrefringência e a maioria encontra-se fragmentada e fraturada, exibindo extinção ondulatória (Fig. 4). Na matriz, os cristais fragmentados de olivina apresentam cor amarelada a esverdeada com pleocroísmo fraco, com alguns cristais formando côndrulos barrados (Fig. 5A).

A maioria dos côndrulos é composta de cristais de olivina, os quais apresentam formas arredondadas a alongadas. Esse mineral também é encontrado incluso em cristais de piroxênio. De acordo com resultados de microsssonda eletrônica (EPMA) para dez cristais (Tab. 1), esta olivina é rica em $\mathrm{Mg}\left(\mathrm{Fa}_{24,2-25,8}-\mathrm{Fo}_{73,7-75,3}\right)$.

0 conteúdo de elementos-traço é bastante uniforme, possuindo teores extremamente baixos $(<0,03 \%)$ de $\mathrm{TiO}_{2}$ e $\mathrm{Al}_{2} \mathrm{O}_{3}$. Os conteúdos de $\mathrm{CaO}$ $(<0,03 \%)$ também são baixos e a concentração de MnO varia de 0,40 a 0,51 \%. Estes valores são coerentes com a média para o meteorito condrítico do tipo L6 Suizhou (Xie \& Chen, 2015). No Rio do Pires, o conteúdo médio de Fa é de 25,2 mol, permitindo representar esta olivina pela fórmula $\left(\mathrm{Mg}_{1.46} \mathrm{Fe}_{0.50} \mathrm{Mn}_{0.01}\right)_{2} \mathrm{SiO}_{4}$.

\section{Piroxênio}

Piroxênio é o segundo mineral em abundância no meteorito Rio do Pires. Os côndrulos de piroxênio são alongados (Fig. 4E), apresentando efeitos típicos de choque tais como baixa birrefringência em tons do cinza, extinção ondulatória, mosaicismo (aglomerados de cristais muito pequenos) e geminação mecânica (Fig. 5A). Em alguns cristais são observadas fraturas planares. Côndrulos radiais são raros e os poucos encontrados apresentam estrutura difusa (Fig. 4D). Análises por EPMA de 9 cristais de piroxênio neste condrito demonstram tratar-se de ortopiroxênio (Fig. 5A) com conteúdo médio de Enstatita variando de 73,4 a $77,3 \%$ e teores de $21,2 \leq \mathrm{Fs} \leq 25,0 \mathrm{~mol}$.

$\begin{array}{llll} & 0 & \text { ortopiroxênio do } & \text { Rio do } \\ \text { Pires é } & \text { representado pela fórmula } \\ \left\{\left(\mathrm{Mg}_{0.759} \mathrm{Fe}_{0.211} \mathrm{Ca}_{0.014}\right)_{0,984}\left(\mathrm{Si}_{1,007} \mathrm{Al}_{0.002}\right)_{1.009} \mathrm{O}_{3}\right\} \text {. As }\end{array}$ concentrações médias dos elementos maiores são respectivamente $\mathrm{SiO}_{2}$ 56,10\%, MgO 28,35\% e FeO 14,09\% e os conteúdos de MnO (0,39-0,48\%) (Tab. 2) são similares aos da olivina $(0,40 \leq \mathrm{MnO} \leq$ $0,51 \%)$. A pequena variação dos elementos maiores de olivina e ortopiroxênio (Fig. 5A) indica que os conteúdos de elementos maiores no condrito Rio do Pires estão em equilíbrio, fato também observado no meteorito condrítico Suizhou (Xie \& Chen, 2015). Os conteúdos de elementos menores são também bastante uniformes e baixos. $\mathrm{TiO}_{2} \mathrm{e}$ $\mathrm{Al}_{2} \mathrm{O}_{3}$ são inferiores a 0,25\%. 0 Cálcio varia de 0,50 a $0,83 \%$. Os teores de $\mathrm{Na}_{2} \mathrm{O}$ e $\mathrm{K}_{2} \mathrm{O}$ estão abaixo do limite de detecção da microssonda eletrônica.

\section{Plagioclásio}

0 plagioclásio é um mineral bastante comum nos meteoritos condríticos dos tipos L5 e L6. No Rio do Pires ocorre como grãos de formato irregular de cor cinza e tamanhos em torno de 70-190 $\mu \mathrm{m}$ (Fig. 5A). Antonello \& Zucolotto (2001) descre- 

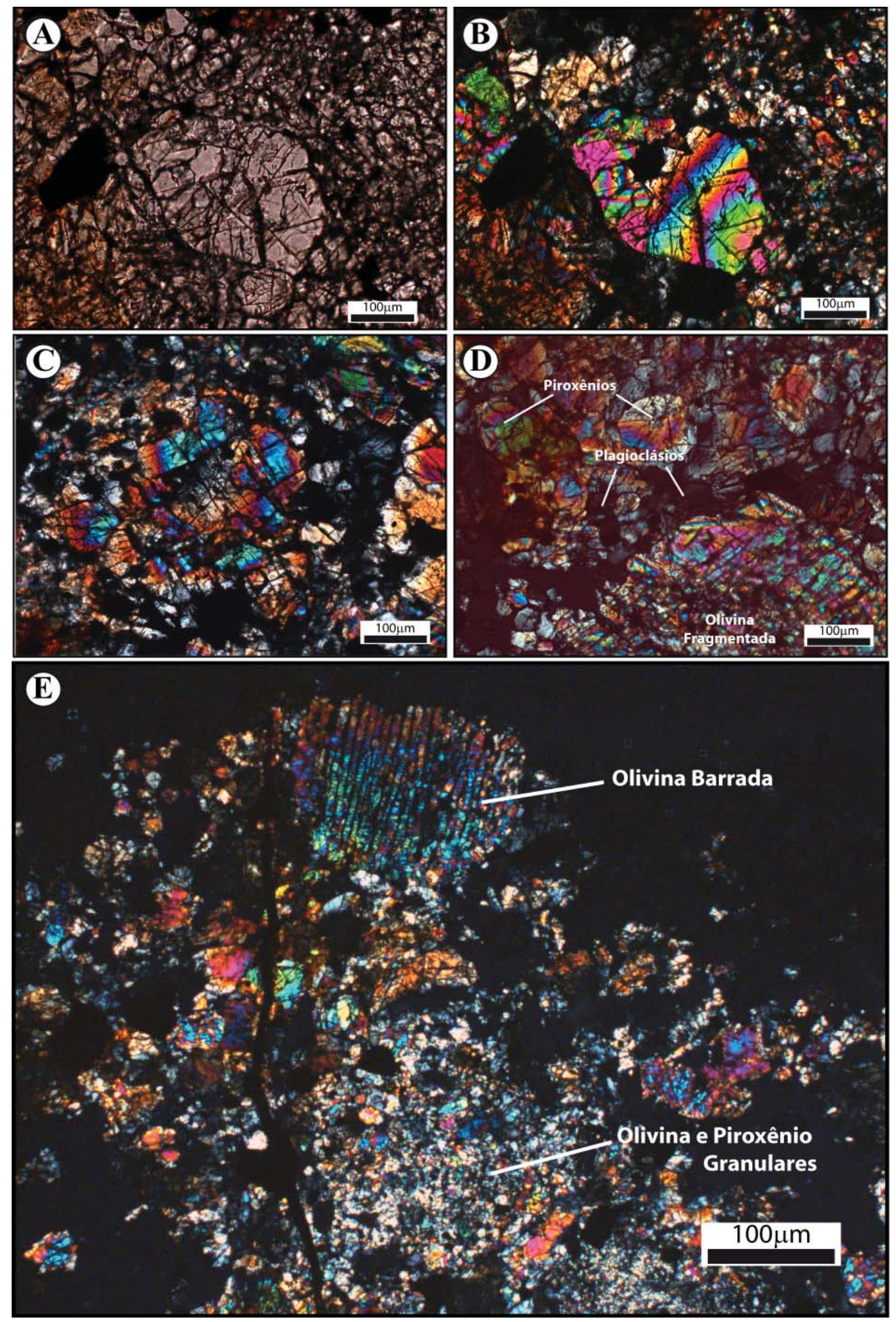

Figura 4. Fotomicrografias de côndrulos imersos na matriz cristalina do meteorito Rio do Pires. Pórfiro de olivina euedral e fragmentada em luz transmitida (A) e (B); Pórfiro de piroxênio em luz polarizada (C); Côndrulo com pórfiros de olivina fragmentada, piroxênio e plagioclásio, em luz polarizada (D); Côndrulo de olivina e piroxênio granulares e côndrulo de olivina barrada, em luz polarizada (E).

Figure 4. Photomicrographs of chondrules imbedded in the crystalline matrix in Rio do Pires meteorite. A euhedral olivine porphyry under transmitted light (A) and polarized light (B); Pyroxene porphyry under polarized light (C); Chondrule with porphyries of fragmented olivine, pyroxene, and plagioclase, under polarized light (D); A granular chondrule of olivine and pyroxene and a chondrule of barred olivine, under polarized light. 

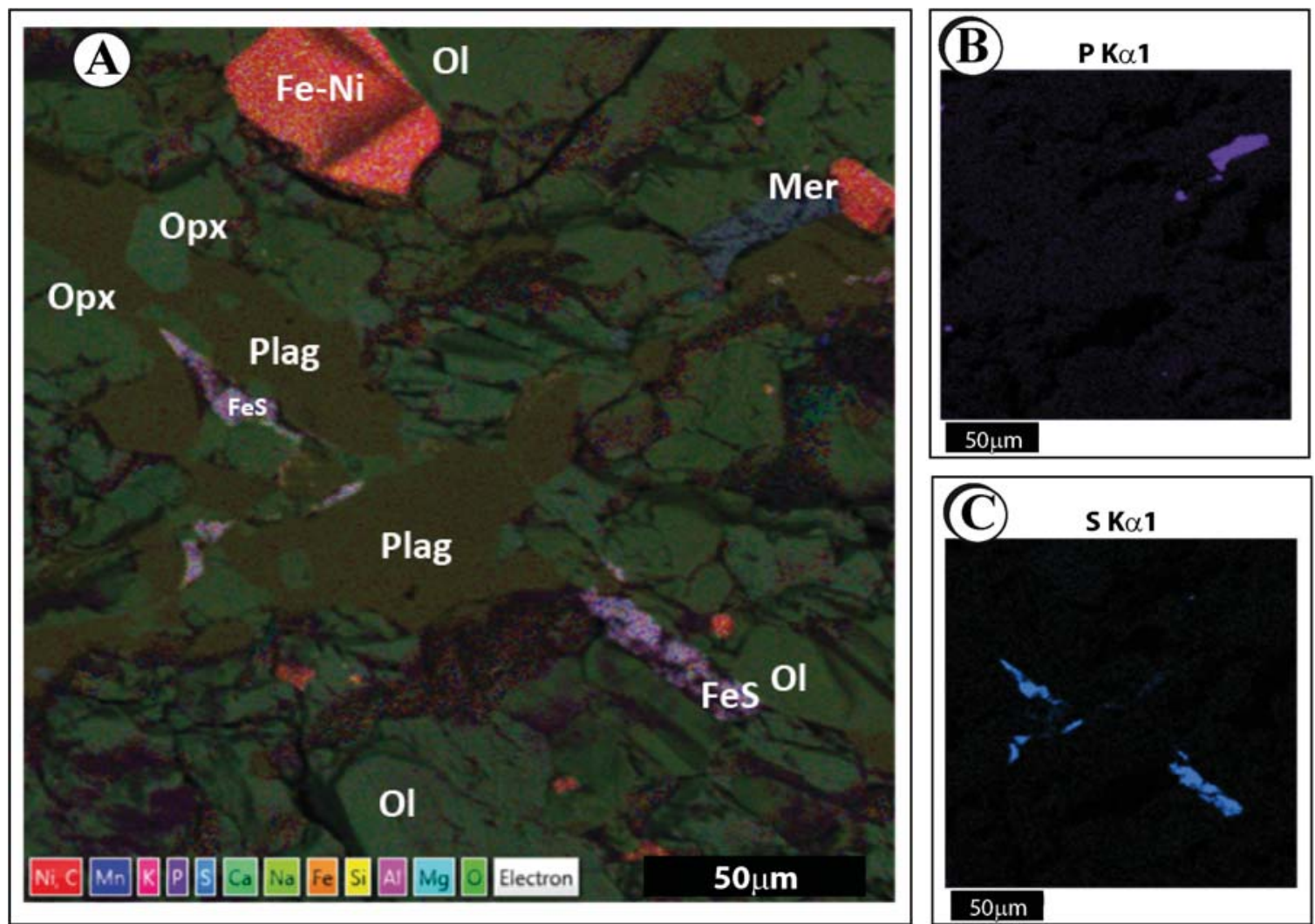

Figura 5. Mapas de varredura por EDS-MEV dos minerais principais observados no meteorito Rio do Pires. A) Campo com olivina, ortopiroxênio, plagioclásio, metal, fosfato e sulfeto; B) Mapa Elemental para o Fósforo; C) Mapa Elemental para o Enxofre. Ol = Olivina, $\mathrm{Opx}=$ Enstatita, $\mathrm{Mer}=$ Merrilita, $\mathrm{Plag}=$ Plagioclásio, $\mathrm{FeS}=$ Troilita, $\mathrm{Fe}-\mathrm{Ni}$ = Liga metálica de ferro e níquel.

Figure 5. Elemental maps by scanning electron microscopy showing minerals observed in Rio do Pires meteorite. A) Study field showing olivine, ortopyroxene, plagioclase, metal, phosphate and sulfide; B) Elemental map of Phosphorus; C) Elemental map of Sulphur. $\mathrm{Ol}=$ Olivine, $\mathrm{Opx}=$ Enstatite, $\mathrm{Mer}=$ Merrilite, Plag = Plagioclase, $\mathrm{FeS}=$ Troilite, $\mathrm{Fe}-\mathrm{Ni}=$ iron-niquel metal alloy.

Tabela 1. Composição química da olivina no meteorito Rio do Pires (wt \%).

Table 1. Chemical composition of the olivine in the Rio do Pires meteorite (wt \%).

\begin{tabular}{|c|c|c|c|c|c|c|c|c|c|c|c|c|}
\hline Amostra & $\begin{array}{l}\text { Suizhou-Olv } \\
\text { (média \#19) }\end{array}$ & 1 & 2 & 3 & 4 & 5 & 6 & 7 & 8 & 9 & 10 & $\begin{array}{c}\text { Média } \\
\# 10\end{array}$ \\
\hline Referência & $\begin{array}{c}\text { Wang et al., } \\
1990\end{array}$ & RP-OI & RP-OI & RP-OI & RP-OI & RP-OI & RP-OI & RP-OI & RP-OI & RP-OI & RP-OI & RP-OI \\
\hline Oxido & $\mathrm{Wt} \%$ & $\mathrm{Wt} \%$ & $\mathrm{Wt} \%$ & $\mathrm{Wt} \%$ & $\mathrm{Wt} \%$ & $\mathrm{Wt} \%$ & $\mathrm{Wt} \%$ & $\mathrm{Wt} \%$ & $\mathrm{Wt} \%$ & $\mathrm{Wt} \%$ & $\mathrm{Wt} \%$ & $\mathrm{Wt} \%$ \\
\hline $\mathrm{SiO}_{2}$ & 38,66 & 38,54 & 38,56 & 38,62 & 38,36 & 38,59 & 38,66 & 39,04 & 38,64 & 38,93 & 38,68 & 38,66 \\
\hline $\mathrm{TiO}_{2}$ & 0,08 & 0,00 & 0,00 & 0,02 & 0,00 & 0,03 & 0,00 & 0,00 & 0,00 & 0,00 & 0,00 & 0,01 \\
\hline $\mathrm{Al}_{2} \mathrm{O}_{3}$ & 0,51 & 0,01 & 0,02 & 0,00 & 0,00 & 0,01 & 0,01 & 0,08 & 0,00 & 0,00 & 0,00 & 0,01 \\
\hline $\mathrm{Cr}_{2} \mathrm{O}_{3}$ & 0,51 & na & na & na & na & na & 0,01 & 0,02 & 0,02 & 0,01 & 0,00 & 0,01 \\
\hline $\mathrm{FeO}$ & 21,76 & 23,31 & 22,98 & 23,13 & 22,89 & 22,94 & 22,69 & 21,92 & 23,25 & 22,87 & 23,12 & 22,91 \\
\hline $\mathrm{MnO}$ & 0,52 & 0,42 & 0,46 & 0,43 & 0,40 & 0,40 & 0,51 & 0,44 & 0,50 & 0,51 & 0,49 & 0,45 \\
\hline MgO & 37,99 & 37,38 & 37,61 & 37,62 & 37,25 & 37,74 & 37,63 & 38,26 & 38,34 & 38,11 & 38,56 & 37,85 \\
\hline $\mathrm{NiO}$ & 0,12 & na & na & na & na & na & 0,04 & 0,00 & 0,01 & 0,00 & 0,01 & 0,01 \\
\hline $\mathrm{CaO}$ & 0,10 & 0,01 & 0,01 & 0,00 & 0,03 & 0,02 & 0,01 & 0,01 & 0,01 & 0,00 & 0,00 & 0,01 \\
\hline TOTAL & 100,25 & 99,67 & 99,63 & 99,83 & $\mathbf{9 8 , 9 3}$ & 99,74 & 99,56 & 99,77 & 100,76 & 100,42 & 100,86 & 99,93 \\
\hline Fo & 75,04 & 73,74 & 74,09 & 74,00 & 74,04 & 74,23 & 74,30 & 75,31 & 74,21 & 74,40 & 74,44 & 74,28 \\
\hline $\mathbf{F a}$ & 24,11 & 25,80 & 25,40 & 25,52 & 25,52 & 25,32 & 25,13 & 24,20 & 25,24 & 25,04 & 25,03 & 25,22 \\
\hline $\mathrm{Te}$ & 0,58 & 0,47 & 0,51 & 0,48 & 0,45 & 0,45 & 0,57 & 0,49 & 0,55 & 0,56 & 0,53 & 0,51 \\
\hline
\end{tabular}

Valores determinados por EPMA. na $=$ não analisado. $\mathrm{Fo}=$ Forsterita, $\mathrm{Fa}=$ Fayalita, $\mathrm{Te}=$ Tephroita

$\mathrm{RP}-\mathrm{Ol}=$ Olivina analisada no meteorito condrítico Rio do Pires (este trabalho). 
vem o plagioclásio como uma fase acessória no Rio do Pires, associado à presença de maskelinita.

Os cristais estudados apresentam formas irregulares, extinção ondulatória e fraturas, feições típicas de choque, ocorrendo como constituinte intersticial na matriz. Não foi possível estimar a razão de plagioclásio/maskelinita.

A composição química do plagioclásio (Tab. 3) nesse meteorito é predominantemente sódica $(80,54<\mathrm{Ab}<83,05)$, com conteúdo pouco variável da molécula de Or $(6,33$ a 7,95) e An $(10,27$ a 11,88). Os dados permitem classificar este plagioclásio como oligoclásio e estabelecer a seguinte fórmula geral: $\left(\mathrm{Na}_{0.74} \mathrm{~K}_{0.06} \mathrm{Ca}_{0.10} \mathrm{Fe}_{0.02}\right)_{0.92} \mathrm{Al}_{1.05}$ $\left(\mathrm{Si}_{2.90} \mathrm{Al}_{0.07}\right)_{3.00} \mathrm{O}_{8}$.

A composição química da maskelinita representada pela fórmula é $\left(\mathrm{Na}_{0.59} \mathrm{~K}_{0.06} \mathrm{Ca}_{0}\right.$ $\left.{ }_{11} \mathrm{Fe}_{0.02}\right)_{0.78} \mathrm{Al}_{1.06}\left(\mathrm{Si}_{2.93} \mathrm{Al}_{0.07}\right)_{3.00} \mathrm{O}_{8}$, calculada a partir de análises MEV realizadas em 14 pontos, sendo muito similar à fórmula do plagioclásio. No sítio $\mathrm{X}$, posição comumente ocupada por $\mathrm{Na}$ e Ca, também é comum encontrar a substituição parcial destes íons por $\mathrm{Ba}, \mathrm{Sr}, \mathrm{Ni}$, Eu e mesmo Cr e outros.

\subsubsection{Minerais opacos}

Os minerais opacos observados nas lâminas do Rio do Pires examinadas neste estudo correspondem a cerca de 5,3\% em volume da rocha, tendo sido identificadas três fases principais: FeNi metal, troilita e cromita. De acordo com Rubin (1997) a razão taenita/kamacita em condritos ordinários do tipo L é de $\sim 0.3$, isto é, possuem concentrações de kamacita 3 vezes maiores que a taenita.

Além dessas duas fases principais é possível identificar quantidades acessórias de tetrataenita, awaruita, pentlandita (em espécimes oxidados), ilmenita, rutilo e cobre metálico que são fases mais raras em abundância ( $<10-4 \mathrm{wt} \%)$, mas bastante frequentes, presentes em aproximadamente $66 \%$ dos condritos já analisados.

\section{Ferro-Níquel metálico}

O Fe-Ni metálico sob a forma de uma solução sólida é um componente muito frequente nos meteoritos rochosos e predominante nos me-

Tabela 2. Composição química do ortopiroxênio no meteorito Rio do Pires (wt \%).

Table 2. Chemical composition of orthopyroxene in the Rio do Pires meteorite (wt \%)

\begin{tabular}{|c|c|c|c|c|c|c|c|c|c|c|c|}
\hline Amostra & $\begin{array}{l}\text { Suizhou-Px } \\
\text { (média \#3) }\end{array}$ & 1 & 2 & 3 & 4 & 5 & 6 & 7 & 8 & 9 & $\begin{array}{c}\text { Média } \\
\# 9\end{array}$ \\
\hline Referência & $\begin{array}{c}\text { Xie \& Chen } \\
2015\end{array}$ & RP-Px & RP-Px & RP-Px & RP-Px & RP-Px & RP-Px & RP-Px & RP-Px & RP-Px & RP-Px \\
\hline Óxido & $\mathrm{Wt} \%$ & $\mathrm{Wt} \%$ & $\mathrm{Wt} \%$ & $\mathrm{Wt} \%$ & $\mathrm{Wt} \%$ & $\mathrm{Wt} \%$ & $\mathrm{Wt} \%$ & $\mathrm{Wt} \%$ & $\mathrm{Wt} \%$ & $\mathrm{Wt} \%$ & $\mathrm{Wt} \%$ \\
\hline $\mathrm{SiO}_{2}$ & 55,78 & 55,91 & 56,14 & 56,32 & 55,93 & 55,96 & 56,02 & 56,10 & 56,27 & 56,27 & 56,10 \\
\hline $\mathrm{TiO}_{2}$ & 0,16 & 0,20 & 0,24 & 0,15 & 0,16 & 0,23 & 0,05 & 0,05 & 0,06 & 0,07 & 0,13 \\
\hline $\mathrm{Al}_{2} \mathrm{O}_{3}$ & 0,16 & 0,13 & 0,17 & 0,17 & 0,16 & 0,16 & 0,04 & 0,02 & 0,04 & 0,05 & 0,10 \\
\hline $\mathrm{Cr}_{2} \mathrm{O}_{3}$ & 0,11 & na & na & na & na & na & 0,07 & 0,10 & 0,06 & 0,05 & 0,03 \\
\hline $\mathrm{FeO}$ & 13,95 & 14,11 & 14,24 & 13,99 & 14,17 & 14,07 & 14,40 & 14,10 & 13,90 & 13,79 & 14,09 \\
\hline $\mathrm{MnO}$ & 0,50 & 0,46 & 0,39 & 0,43 & 0,48 & 0,44 & 0,16 & 0,02 & 0,00 & 0,03 & 0,27 \\
\hline $\mathrm{MgO}$ & 29,24 & 28,47 & 28,35 & 28,26 & 28,06 & 28,38 & 27,55 & 29,10 & 28,57 & 28,45 & 28,35 \\
\hline $\mathrm{CaO}$ & 0,72 & 0,75 & 0,67 & 0,66 & 0,71 & 0,75 & 0,83 & 0,80 & 0,65 & 0,50 & 0,70 \\
\hline $\mathrm{Na}_{2} \mathrm{O}$ & 0,04 & na & na & na & na & na & na & na & na & na & na \\
\hline $\mathrm{K}_{2} \mathrm{O}$ & 0,01 & na & na & na & na & na & na & na & na & na & na \\
\hline Total & 100,66 & 100,03 & 100,20 & 99,99 & 99,66 & 99,99 & 99,11 & 100,27 & 99,54 & 99,21 & 99,78 \\
\hline En & 78,84 & 76,24 & 75,49 & 75,13 & 75,17 & 75,87 & 73,45 & 77,30 & 75,64 & 75,33 & 75,51 \\
\hline Fs & 19,77 & 22,31 & 23,23 & 23,61 & 23,46 & 22,68 & 24,97 & 21,17 & 23,12 & 23,73 & 23,14 \\
\hline Wo & 1,39 & 1,45 & 1,29 & 1,26 & 1,37 & 1,45 & 1,58 & 1,53 & 1,23 & 0,94 & 1,34 \\
\hline
\end{tabular}

Valores determinados por EPMA. na = não analisado. $\mathrm{En}=$ Enstatita, $\mathrm{Fs}=$ Ferrosilita, Wo $=$ Wollastonita.

$\mathrm{RP}-\mathrm{Px}=$ Piroxênio analisado no meteorito condrítico Rio do Pires (este trabalho). 
Tabela 3. Composição química do plagioclásio no meteorito Rio do Pires (wt \%). Table 3. Chemical composition of plagioclase in the Rio do Pires meteorite (wt \%).

\begin{tabular}{|c|c|c|c|c|c|c|c|c|}
\hline Óxido (wt\%) & $\begin{array}{l}\text { Suizhou Plag } \\
\text { (Média 3) }\end{array}$ & 1 & 2 & 3 & 4 & 5 & 6 & Média \#6 \\
\hline Referência & $\begin{array}{c}\text { Xie \& Chen } \\
2015\end{array}$ & RP-Plag & RP-Plag & RP-Plag & RP-Plag & RP-Plag & RP-Plag & RP-Plag \\
\hline Óxido & $\mathrm{Wt} \%$ & $\mathrm{Wt} \%$ & $\mathrm{Wt} \%$ & $\mathrm{Wt} \%$ & $\mathrm{Wt} \%$ & $\mathrm{Wt} \%$ & $\mathrm{Wt} \%$ & $\mathrm{Wt} \%$ \\
\hline$\overline{\mathrm{SiO}_{2}}$ & 65,76 & 64,50 & 64,30 & 66,40 & 66,70 & 65,80 & 65,90 & 65,60 \\
\hline $\mathrm{TiO}_{2}$ & 0,04 & na & na & na & na & na & na & na \\
\hline $\mathrm{Al}_{2} \mathrm{O}_{3}$ & 21,77 & 22,80 & 22,90 & 21,50 & 21,30 & 21,00 & 21,30 & 21,80 \\
\hline $\mathrm{FeO}$ & 0,41 & 0,30 & 0,60 & 0,50 & 0,50 & 0,40 & 0,50 & 0,47 \\
\hline $\mathrm{MnO}$ & 0,02 & na & na & na & na & na & na & na \\
\hline MgO & na & 0,00 & 0,00 & 0,00 & 0,00 & 0,00 & 0,10 & 0,02 \\
\hline $\mathrm{CaO}$ & 2,21 & 2,30 & 2,00 & 2,10 & 2,00 & 2,20 & 2,30 & 2,15 \\
\hline $\mathrm{Na}_{2} \mathrm{O}$ & 8,87 & 8,80 & 8,80 & 8,40 & 8,60 & 9,50 & 8,70 & 8,80 \\
\hline $\mathrm{K}_{2} \mathrm{O}$ & 1,31 & 1,30 & 1,30 & 1,10 & 1,00 & 1,10 & 1,10 & 1,15 \\
\hline $\mathrm{BaO}$ & 0,02 & na & na & na & na & na & na & na \\
\hline TOTAL & 100,41 & 100,00 & 99,90 & 100,00 & 100,10 & 100,00 & 99,90 & 99,98 \\
\hline$\overline{\text { Or }}$ & 7,89 & 7,83 & 7,95 & 7,04 & 6,35 & 6,33 & 6,77 & $\overline{7,04}$ \\
\hline $\mathbf{A b}$ & 80,97 & 80,54 & 81,78 & 81,68 & 82,99 & 83,05 & 81,35 & 81,90 \\
\hline An & 11,15 & 11,63 & 10,27 & 11,28 & 10,66 & 10,63 & 11,88 & 11,06 \\
\hline
\end{tabular}

Valores determinados por EDS-MEV. na = não analisado. $\mathrm{Or}=$ Ortoclásio. $\mathrm{Ab}=$ Albita. $\mathrm{Na}=$ Anortita .

RP-Plag = Plagioclásio analisado no meteorito condrítico Rio do Pires (este trabalho).

tálicos e palasitos (mistos). A concentração de $\mathrm{Ni}$ nessa liga nos condritos ordinários varia de 7 a 45 wt\% (Oshtrakh et al., 2008). Os três minerais que compõem a solução sólida Fe-Ni metálico são denominados: i) kamacita ( $\alpha \mathrm{Fe}-\mathrm{Ni})$, ii) taenita $(\gamma \mathrm{Fe}-$ Ni) e iii) plessita, uma mistura de kamacita e taenita granulares, com conteúdo de Ni de 20-25 wt\%.

O Fe-Ni metálico é a fase majoritária entre os minerais opacos do meteorito Rio do Pires, possuindo distribuição heterogênea. A análise ocorreu após uma amostra ser tratada com nital (solução $\mathrm{HNO}_{3}, \mathrm{C}_{2} \mathrm{H}_{6} \mathrm{O}$ a $2 \%$ ) revelando a liga de $\mathrm{Fe}-\mathrm{Ni}$ (Fig. 3C) em suas diversas formas, sobressaindo-se a kamacita hachuriada e kamacita com bandas de Neumann, taenita zonada e não zonada e tetrataenita, uma fase rara em condritos. Ocorrências de plessita e martensita também foram observadas (Fig. 6).

Os cristais metálicos de Fe-Ni do meteorito Rio do Pires sob luz refletida apresentam cor branca metálica, tem formato irregular e tamanho variando desde partículas micrométricas a grãos milimétricos. $\mathrm{O}$ conteúdo de $\mathrm{Ni}$ nessa liga varia de 5 a 32\%. Medidas realizadas com EDS demonstram homogeneidade da kamacita $(\mathrm{Fe}=94,2$ a 95,0\%, $\mathrm{Ni}=5,0$ a $5,8 \%$ e Co $=0,81$ a $0,87 \%$ ), que ocorre como grãos individuais e como agregados policristalinos. Por sua vez, a taenita, naturalmente mais rica em $\mathrm{Ni}$ que a kamacita, possui um conteúdo médio de Fe de 76,36 wt \% e Ni de 23,63 wt \%. A plessita, uma mistura de kamacita e taenita,também está presente entre os minerais opacos desse meteorito, apresentando-se zonada - referida por alguns autores como taenita, e não zonada - também denominada plessita propriamente dita.

Nos cristais de kamacita existem numerosas linhas paralelas, denominadas bandas de Neumann (Buchwald, 1975) que são lamelas geminadas produzidas por choque (Fig. 6A).

Observou-se ainda a martensita (Fig. 6B) solução-sólida de ferro-carbono que forma cristais lenticulares - em textura intragranular. Estes cristais de martensita são provavelmente resultantes da decomposição da taenita e sua presença é um indicador de distúrbios produzidos por choque sofrido pelo meteorito no espaço (Xie \& Chen, 2015). 

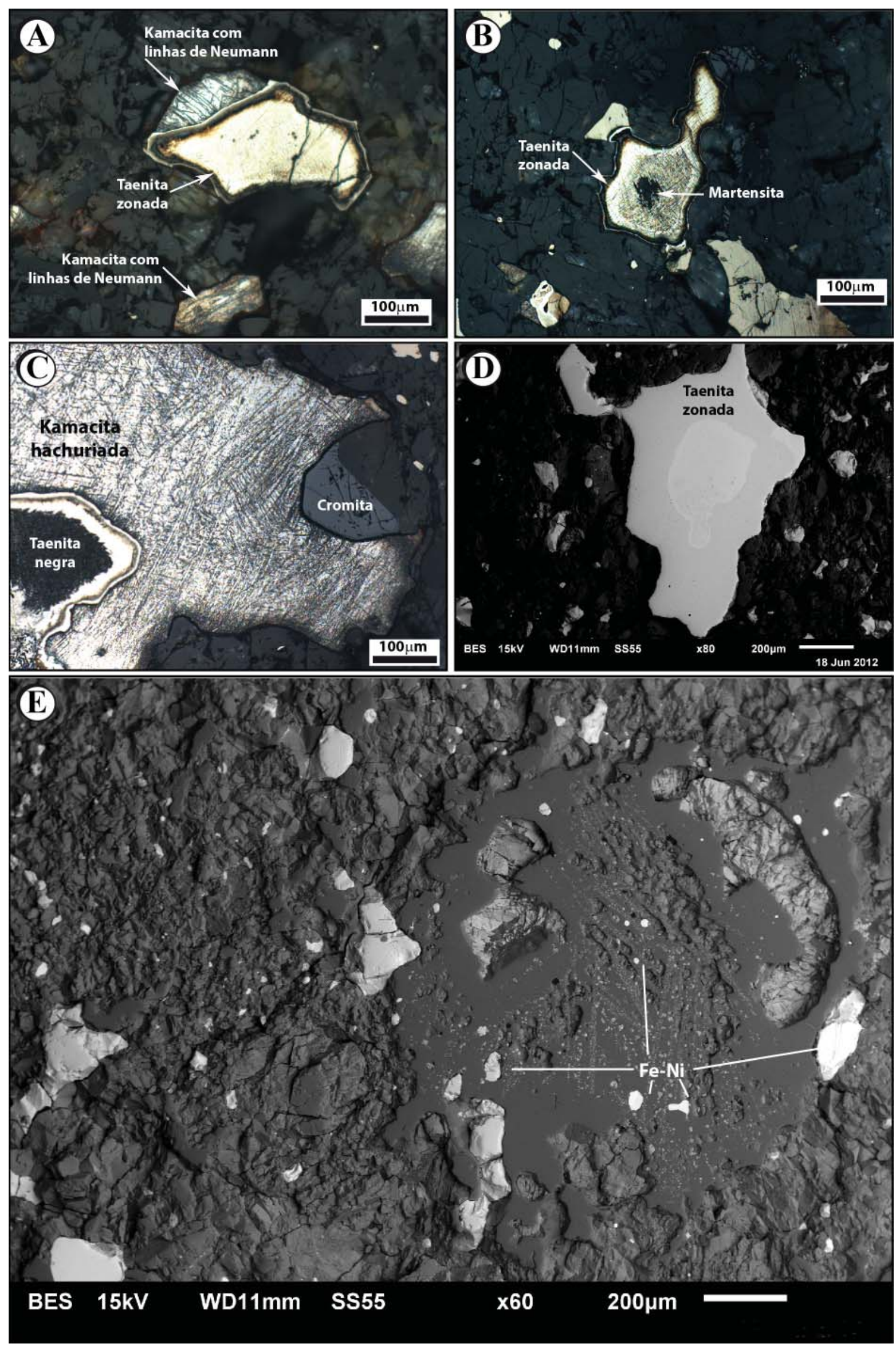

Figura 6. Fases metálicas de Fe-Ni. A) Kamacita com linhas de Neumann e taenita zonada; B) Taenita e martensita; C) Kamacita hachuriada e taenita negra; D) Taenita zonada; E) Vestígios de côndrulo com inclusões de Fe-Ni.

Figure 6. Fe-Ni metal phases. A) Kamacite with Neumann lines and zoned taenite; B) Taenite and martensite; C) Hatched kamacite and black taenita; D) Zoned taenite; E) Chondrule remnants with $\mathrm{Fe}-\mathrm{Ni}$ inclusions. 


\section{Ferro-Níquel metálico: Troilita}

Esse sulfeto de ferro com fórmula geral $\mathrm{FeS}$ foi primeiramente observado pelo monge italiano Dominique Troili (Troili, 1766) no meteorito condrito Albareto que caiu na Itália em 1766. Contudo, apenas em 1862 este sulfeto foi identificado como um novo mineral por Gustav Rose, que o denominou troilita em homenagem ao monge (Marvin, 2001). É um mineral muito comum nos meteoritos, porém de raríssima ocorrência na crosta terrestre.

A troilita apresenta-se no meteorito Rio do Pires em grãos arredondados ou alongados, de cor dourada, cuja composição química média consiste de $65,5 \%$ Fe e $34,5 \%$ S (Fig. 5A e 5C). Não foram observados efeitos de choque nos grãos de troilita examinados, a exemplo de mosaicismo, texturas intragranulares ou indícios de fusão por impacto (Fig. 7).
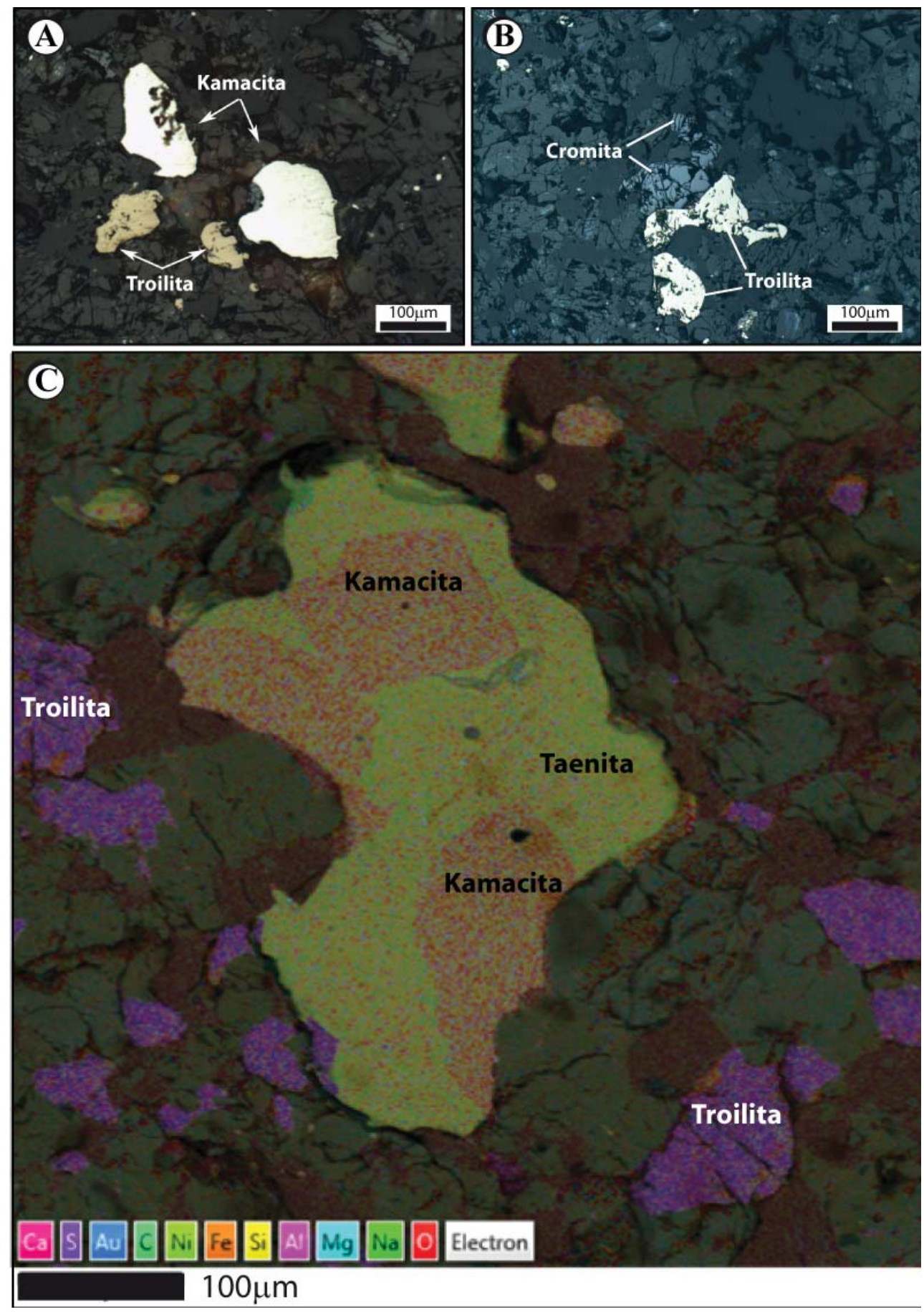

Figura 7. Imagens de texturas apresentadas por minerais opacos. A) Liga Fe-Ni e troilita; B) Troilita e cromita; C) Mapa da distribuição dos elementos analisados por varredura no MEV. Nas imagens são destacados cristais de: troilita, kamacita e taenita. Figure 7. Images of textures presented by opaque minerals. A) Fe-Ni alloy and troilite; (B) Troilite and cromite; (C) Elemental mapping by scanning electron microscopy. Crystals of troilite, kamacite and taenite outstanding in the image. 


\section{Ferro-Níquel metálico: Cromita}

Cromita $\left(\mathrm{FeCr}_{2} \mathrm{O}_{4}\right)$ é um mineral acessório muito comum em condritos, apresentando-se no meteorito Rio do Pires em cristais de formato irregular, sem fraturas ou deformações planares visíveis. Seu conteúdo médio de Cr chega a 57,8\% (Fig. 7B).

\section{Ferro-Níquel metálico: Fosfatos}

Fosfatos de cálcio como a cloroapatita e merrilita - quando presentes em meteoritos condritos e acondritos - são potencialmente elegíveis para estudos geocronológicos baseados no sistema U-Pb. No meteorito Rio do Pires foram identificados cristais de whitlockita (merrilita) com a seguinte composição básica (teores em peso): $\mathrm{CaO}$ $44,03 \%, \mathrm{P}_{2} \mathrm{O}_{5} 41,25 \%, \mathrm{MgO} 4,26 \%$ e $\mathrm{Na}_{2} \mathrm{O} 2,56 \%$ ( $\sim 6$ pontos analisados por EDS-MEV; Fig. $5 \mathrm{~A}$ e B).

\section{Discussão dos resultados}

Os estudos aqui apresentados ampliam o conhecimento sobre o condrito Rio do Pires e confirmam sua classificação.

A textura, pobre em côndrulos bem definidos, e o percentual da molécula da fayalita nos cristais de olivina $\left(\mathrm{Fa}_{25}\right)$ são características dos meteoritos do grupo L. A existência de grãos de feldspatos maiores que $50 \mu \mathrm{m}$ e a concentração de Co na kamacita $(0,88 \%)$, permitem sub-classificar Rio do Pires como L6, de acordo com os critérios de Van Schmus \& Wood (1967), ratificando assim a classificação prévia realizada quando este condrito foi registrado no Meteoritical Bulletin (Wlotzka, 1994).

\subsection{Efeitos do choque e metamorfismo}

Stöffler et al. (1991) defenderam que os cristais de plagioclásio nos condritos ordinários preservam evidências dos efeitos de choque. De acordo com estes autores, um choque de baixa intensidade resulta em extinção ondulatória; feições de deformação planar (PDFs) e isotropização parcial ocorrem em choques de intensidade moderada; e a completa transformação em vidro diaplético (maskelinita) acontece quando a rocha é submetida a choques de graus mais elevados.

A estrutura interna do meteorito Rio do Pires, observada com lupa em amostra de mão serrada, permite visualizar diversos veios (Fig. 2B), os quais são indicadores de choque metamórfico decorrente de impacto sofrido no espaço. Os veios de choque observados no meteorito Rio do Pires são muito finos, retilíneos e simples, similares a fraturas, e comparáveis aos descritos no condrito Suizhou por Xie \& Chen (2015).

Alguns outros efeitos sugestivos de choque metamórfico (Stöffler et al., 1991; Rubin 1997) são encontrados nos cristais de olivina e plagioclásio do meteorito Rio do Pires. Fraturas irregulares, mosaicismo e extinção ondulatória, tais como os visualizados, são parâmetros indicativos de choque de grau moderado, e classificariam meteorito Rio do Pires entre S3 e S4 na escala de Stöffler et al. (1991) conforme quadro 1. Contudo, a presença de veios de choque e maskelinita - um vidro proveniente da fusão do plagioclásio sob alta pressão - elevam o grau de choque de S3-S4 para S5, sinalizando que o mesmo foi submetido a condições de alta pressão e temperatura, as quais podem ter alcançado valores entre $45-55 \mathrm{GPa}$ e $600-850^{\circ} \mathrm{C}$.

A classificação baseada nos dados obtidos neste trabalho difere daquela proposta por Brearley (Wlotzka, 1994), que atribui grau de choque S6 ao Rio do Pires nas informações preliminares prestadas ao Metoritical Bulletin para registro do meteorito. Essa nova proposição, ao incluir a existência de múltiplos veios de fusão como fator determinante para a classificação entre S4 e S5, complementa os resultados de Antonello \& Zucolotto (2001), que sugeriram grau de choque entre S3 e S4.

\subsection{Efeitos do intemperismo terrestre}

O meteorito Rio do Pires provavelmente foi coletado pouco tempo após a queda, haja vista apresentar baixo grau de intemperismo (Quadro 2) de acordo com os critérios da escala de Wlotzka (1993).

A superfície de corte do meteorito exibe pontos de oxidação da liga $\mathrm{Fe}-\mathrm{Ni}$, com ocorrência em maior intensidade nas zonas adjacentes aos 
Quadro 1. Graus progressivos de metamorfismo de impacto em condritos ordinários, segundo Stöffler et al. (1991). Chart 1. Progressive degrees of impact metamorphism in ordinary chondrites Stöffler et al. (1991).

\begin{tabular}{|c|c|c|c|c|c|}
\hline \multirow{2}{*}{ Grau de Choque } & \multicolumn{2}{|c|}{$\begin{array}{c}\text { Efeitos resultantes do pico de equilíbrio da pressão de } \\
\text { choque em cristais de }\end{array}$} & \multirow{2}{*}{$\begin{array}{l}\text { Efeitos resultantes da } \\
\text { mobilização local da T-P }\end{array}$} & \multirow{2}{*}{$\begin{array}{c}\text { Pressão do } \\
\text { Impacto } \\
\text { (Gpa) }\end{array}$} & \multirow{2}{*}{$\begin{array}{c}\text { Aumento } \\
\text { Temperatura } \\
\text { Pós-Choque } \\
\left({ }^{\circ} \mathrm{C}\right)\end{array}$} \\
\hline & Olivina & Plagioclásio & & & \\
\hline $\begin{array}{c}\text { S1 } \\
\text { Sem choque }\end{array}$ & \multicolumn{2}{|c|}{ Extinção ótica bcm nítida c dcfinida, fraturas irregularcs } & Nenhum & $<4-5$ & $10-20$ \\
\hline $\begin{array}{c}\text { S2 } \\
\text { Choque Muito } \\
\text { Fraco }\end{array}$ & \multicolumn{2}{|c|}{ Extinção ótica ondulatória, fraturas irregulares } & Nenhum & $5-10$ & $20-50$ \\
\hline $\begin{array}{c}\text { S3 } \\
\text { Choque Fraco }\end{array}$ & $\begin{array}{c}\text { Fcições planares, extinção } \\
\text { ondulatória, fraturas } \\
\text { irregulares }\end{array}$ & Extinção ondulatória & $\begin{array}{l}\text { Veios de choque opacos, } \\
\text { formação incipiente de } \\
\text { bolsões de fusão, algumas } \\
\text { vezes interconectados }\end{array}$ & $15-20$ & $100-150$ \\
\hline $\begin{array}{c}\text { S4 } \\
\text { Choque Moderado }\end{array}$ & $\begin{array}{c}\text { Mosaicismo fraco, fraturas } \\
\text { planares }\end{array}$ & $\begin{array}{c}\text { Extinção ondulatória, } \\
\text { isotropismo parcial, feições } \\
\text { de deformação }\end{array}$ & $\begin{array}{c}\text { Bolsões de fusão, veios de } \\
\text { fusão interconectados, veios } \\
\text { de choque opacos }\end{array}$ & $30-35$ & $250-350$ \\
\hline $\begin{array}{c}\text { S5 } \\
\text { Choque Forte }\end{array}$ & $\begin{array}{l}\text { Mosaicismo forte, fraturas } \\
\text { planares + feições de } \\
\text { deformações planares }\end{array}$ & Maskelinita & $\begin{array}{l}\text { Formação de bolsões de } \\
\text { fusão pervasivos }\end{array}$ & $45-55$ & $600-850$ \\
\hline S6 & \multicolumn{2}{|c|}{$\begin{array}{l}\text { Efcitos restritos a regiôcs localizadas no intcior ou } \\
\text { próximo a zonas fundidas }\end{array}$} & & \multirow{3}{*}{$75-90$} & \multirow{3}{*}{$1500-1750$} \\
\hline $\begin{array}{l}\text { Choque Muito } \\
\text { Forte }\end{array}$ & $\begin{array}{l}\text { Recristalização cm cstado } \\
\text { sólido c manchas, } \\
\text { ringwoodita, fusão }\end{array}$ & $\begin{array}{l}\text { Fusão por choque (vidro } \\
\text { normal) }\end{array}$ & $\begin{array}{l}\text { Formação de bolsões de } \\
\text { fusão pervasivos }\end{array}$ & & \\
\hline Choque de Fusão & \multicolumn{3}{|c|}{ Fusão total da rocha (rochas fundidas por impacto e brechas de fusão) } & & \\
\hline
\end{tabular}

Quadro 2. Graus progressivos de intemperismo em condritos ordinários (Wlotzka, 1993).

Chart 2. Progressive weathering degrees in ordinary chondrites (Wlotzka, 1993).

\begin{tabular}{|c|l|}
\hline $\begin{array}{c}\text { Graus de } \\
\text { Intemperismo }\end{array}$ & Feições Observadas (em lâmina delgado-polida sob microscópio petrográfico) \\
\hline W0 & $\begin{array}{l}\text { Não são visíveis sinais de oxidação no metal ou sulfeto. Uma mancha de limonita pode estar } \\
\text { eisivel sob luz transmitida. Quedas recentes usualmente são desse grau de intemperismo, }\end{array}$ \\
\hline W1 & Pequenas bordas de óxidos em volta do metal e troilita; pequenos veios de óxidos. \\
\hline W2 & Oxidação moderada do metal, cerca de 20-60\% sendo afetado. \\
\hline W3 & Oxidação intensa do metal e sulfeto, 60-95\% sendo substituídos. \\
\hline W4 & Completa oxidação ( $>95 \%$ ) do metal e troilita, mas não há alteração nos silicatos. \\
\hline W5 & Início de alteração de silicatos máficos, principalmente ao longo de fissuras. \\
\hline W6 & Substituição massiva de silicatos por minerais argilosos e óxidos. \\
\hline
\end{tabular}


veios de choque, contudo sem afetar a kamacita. Os óxidos formados percolam as fraturas dos minerais, revelando-se sob a forma de manchas de tons amarelo-ocre que ocupam menos de $10 \%$ do volume total do meteorito, características típicas do estágio W1 - ligeiramente intemperizado - em uma escala cujo limite inferior é W0 e o superior W6.

\section{Conclusões}

Os recentes avanços tecnológicos e instrumentais permitem reanalisar amostras de meteoritos de maneira não destrutiva, proporcionando a obtenção de imagens de alta resolução e análises químicas pontuais de melhor precisão e avaliar fases minerais diminutas e de menor expressão modal, bem como feições submicroscópicas, tais como os veios de impacto. As análises quantitativas e semi-quantitativas aqui realizadas por EPMA e EDS, bem como as determinações modais realizadas nos estudos petrográficos, confirmam que o espécime de meteorito Rio do Pires estudado é um condrito ordinário do tipo petrológico L6, tendo como minerais formadores do meteorito cristais de olivina rica na molécula de forsterita, ortopiroxênio enstatita e oligoclásio. Os cristais de olivina, enstatita e oligoclásio perfazem cerca de $85 \%$ em volume do meterorito. Os cristais de olivina e enstatita estão majoritariamente fragmentados, formando texturas em mosaico, enquanto os cristais de plagioclásio foram parcial ou totalmente transformados em maskelinita.

Os minerais de Fe-Ni (kamacita, taenita e plessita), troilita e fosfatos (cloroapatita, merrilita) são os acessórios mais comuns neste condrito. Cromita ocorre em pequenas quantidades. Por outro lado, a identificação do fosfato whitlockita (merrilita) entre as fases minerais dessa rocha pode viabilizar estudos posteriores para a determinação da idade de formação do corpo parental através do sistema cronológico U-Pb.

Várias texturas observadas são características de metamorfismo de impacto. Além disto, o metamorfismo térmico alterou significativamente o condrito Rio do Pires textural e composicionalmente, levando à recristalização dos côndrulos, com perda de nitidez das bordas e homogeneiza- ção dos minerais dos côndrulos e matriz marcada pela ausência de zoneamentos químicos significativos.

Brearley propôs para o condrito Rio do Pires o grau de choque 6 (Wlotzka, 1994). Contudo, devido às texturas observadas em cristais de olivina e plagioclásio, a formação da maskelinita, o fraco mosaicismo, e a presença de fraturas planares, somadas à ausência de ringwoodita e majorita levam a advogar para esta rocha um grau de choque S4S5, reforçando a sugestão de Antonello \& Zucolotto (2001), que propuseram um grau de choque mais fraco que o originalmente adotado no processo de registro desse meteorito.

A presença de veios de choque, em associação com as feições observadas nos cristais de olivina e enstatita, são evidências das colisões que o corpo parental sofreu em tempos muito anteriores à queda dessa amostra na Terra.

Agradecimentos. Os autores expressam aqui seus agradecimentos a Umberto Cordani e Júlio Mendes, cujos comentários muito enriqueceram a versão final deste manuscrito. Agradecem também aos técnicos e pesquisadores do Labsonda da UFRJ, Laboratório Multiusuário da UFS, Laboratório Multiusuário de Microscopia Eletrônica (LAMUME) do IF-UFBA, Museu Nacional, Museu Geológico da Bahia, e ao Laboratório de Preparação e Análise de Amostras do Serviço Geológico do Brasil (CPRM-Salvador) pela preparação de amostras e análises realizadas. Este trabalho conta com recursos dos projetos GeoLogar: Ciências da Terra para a Sociedade (Processos 559013/2009-4 do CNPq e TO: PES 0056/2011 da FAPESB). Débora Rios e Herbet Conceição agradecem ao CNPq pelas bolsas de produtividade em pesquisa. Murilo Gomes agradece ao SISBIC-UFBA pela oportunidade de desenvolver estágio de iniciação científica como aluno voluntário.

\section{Referências bibliográficas}

Amelin Y., Krot A.N., Hutcheon I.D. \& Ulyanov A.A. 2002. Lead isotopic ages of chondrules and calcium-aluminum-rich inclusions. Science, 297:1678-1683.

Antonello, L.L. \& Zucolotto, M.E. 2001. Mineralogy 
and petrography of the L6 chondrite Rio do Pires, Brazil. Acta Microscopica, 3: 234-234.

Chen, M. \& El Goresy, A. 2000. The nature of maskelynite in shocked meteorites: Not diaplectic glass but a glass quenched from shock-induced dense melt at high pressures. Earth and Planetary Science Letters, v.179: 489502.

Buchwald, V.F. 1975. Handbook of iron meteorites: Their history, distribution, composition, and structure. Berkeley, University of California Press. Vols. 1418 p.

Grossman, J. 2017. Meteoritical Bulletin Database. Disponível em: http://www.lpi.usra.edu/ meteor/index.php. Acesso em: 13 jan. 2017.

Hewins, R.H \& Connolly Jr., H.C. 1996. Peak temperatures of flash-melted chondrules. In: Hewins, R. H. \& Scott, E. (Eds). Chondrules and the protoplanetary disk. Cambridge, Cambridge University Press, p. 197-204.

Hutchison, R. 2004. Meteorites: a petrologic, chemical and isotopic synthesis. Cambridge, Cambridge University Press,. 520p.

Krot, A.N., Keil, K., Goodrich, C. A., Scott, R.D. \& Weissberg, N.K. 2005. Classification of meteorites, In: Holland, H.D. \& Turekian, K.K. (Eds.) Meteorites, comets and planets: Treatise of Geochemistry. Elsevier-Pergamon, p. 83-128.

Marvin, U.B. 2001. The fall at Albareto, 1766: Described as volcanic by Domenico Troili. Meteoritics \& Planetary Science, 36(S9): A123.

McSween Jr., H. Y., Lauretta, D. S. \& Leshin, L. A. 2006. Recent Advances in Meteoritics and Cosmochemistry, In: Lauretta, D.S. \& McSween Jr., H.Y. (Eds.) Meteorites and the Early Solar System II), Tucson, The University of Arizona, p. 53-66.

Messenger, S., Sandford, S. \& Brownlee, D. 2006. The Population of Starting Materials Available for Solar System Construction, In: Lauretta, D.S \& McSween Jr., H.Y. (Eds.) Meteorites and the Early Solar System II), Tucson, The University of Arizona, p. 187-208.
National Institutes of Health. 2013. Aplication ImageJ. disponivel em https://imagej.nih.gov/ ij/

Oshtrakh, M.I., Petrova, E.V., Grokhovsky, V.I. \& Semionkin, V.A. 2008. A study of ordinary chondrites by Mössbauer spectroscopy with high-velocity resolution. Meteoritics \& Planetary Science, 43: 941-958.

Rubin, A.E. 1997. Mineralogy of Meteorite Groups. Meteoritics \& Planetary Science 32: 231-247.

Stöffler, D., Keil, K. \& Scott E.R.D. 1991. Shock metamorphism of ordinary chondrites. Geochimica et Cosmochimica Acta, 55: 38453867.

Troili, D. 1766. Regionamento della caduta di un sasso. Modena,. Bartolomeo Soliani Stamp, 43p.

Van Schmus W.R. \& Wood, J.A. 1967. A chemicalpetrologic classification for the chondritic meteorites. Geochimica et Cosmochimica Acta, 31: 747-765.

Weisberg, M.K., Smith, C., Benedix, G., Herds, D.K., Righter, K., Haack, H., Yamaguchi, A., Righter, K., Haack, H. Yamaguchi, A., Y., Aoudjehane, H.C. \& Grossman, J.N. 2009. The Meteoritical Bulletin, 96. Meteoritics and Planetary Science, 44(9): 1365-1397.

Wlotzka, F. 1993. A weathering scale for the ordinary chondrites. Meteoritics, 28(3): 460460

Wlotzka, F. 1994. Meteoritical Bulletin 77. Meteoritics, 29(6): 891-897.

Xie, X.\& Chen, M. 2015. Suizhou meteorite: mineralogy and shock metamorphism. Berlin, Springer-Verlag, $257 \mathrm{p}$. 